\title{
UNSTEADY-STATE INTERPHASE DIFFUSION
}

\author{
R. Chebbi \\ Assistant Professor \\ Department of Chemical Engineering, Qatar University \\ Doha, Qatar.
}

\begin{abstract}
This study is concerned with the problem of unsteady interphase diffusion for multicomponent dilute solutions. An integral technique, based on an approximate boundary-layer approach is used. Results are in good agreement with the exact solution available for the particular case of binary mixtures.
\end{abstract}

\section{NOMENCLATURE}

$\mathrm{C}_{\mathrm{kI}} \quad$ Concentration of component $\mathrm{k}$ in phase $\mathrm{I}$

$\mathrm{C}_{\mathrm{kII}}$ Concentration of component $\mathrm{k}$ in phase II

$D_{k I}$ Diffusion coefficient of component $k$ in phase I

$D_{k I I}$ Diffusion coefficient of component $k$ in phase II

f Approximate concentration profile

i Superscript denoting interfacial conditions

$k$ Subscript denoting component number

$\mathbf{m}_{k} \quad$ Distribution coefficient of component $k$

$\mathrm{N}_{\mathrm{k}} \quad$ Molar flux of component $\mathrm{k}$

o Superscript denoting initial conditions

t Time

z Rectangular coordinate

$\delta$ Boundary layer thickness for the concentration profile

$\varsigma$ Dimensionless z-coordinate 


\section{INTRODUCTION}

The problem of mass transfer of one single substance, present in small quantities, between two immiscible solvents was investigated previously by Marshall et al. (1947), and Scott et al. (1951). A presentation of the problem, including the governing equations, was made by Bird et al. (1960). The method of solution used by previous investigators was an exact one. The coupling between the governing equations was solved by the Laplace transform technique.

In our present analysis, we generalize the treatment and consider mass transfer of $n$ components between two immiscible solvents I and II. We make the assumption that all $\mathbf{n}$ components are present in small quantities. In contrast with the technique of solution previously used by other investigators, we propose an approximate solution based on a boundary-layer approach.

\section{GOVERNING EQUATIONS}

Figure 1 depicts the system of concern. Solvents I and II are assumed to be of infinite dimensions. The two immiscible solvents are separated by an interface located at $\mathrm{z}=0$.

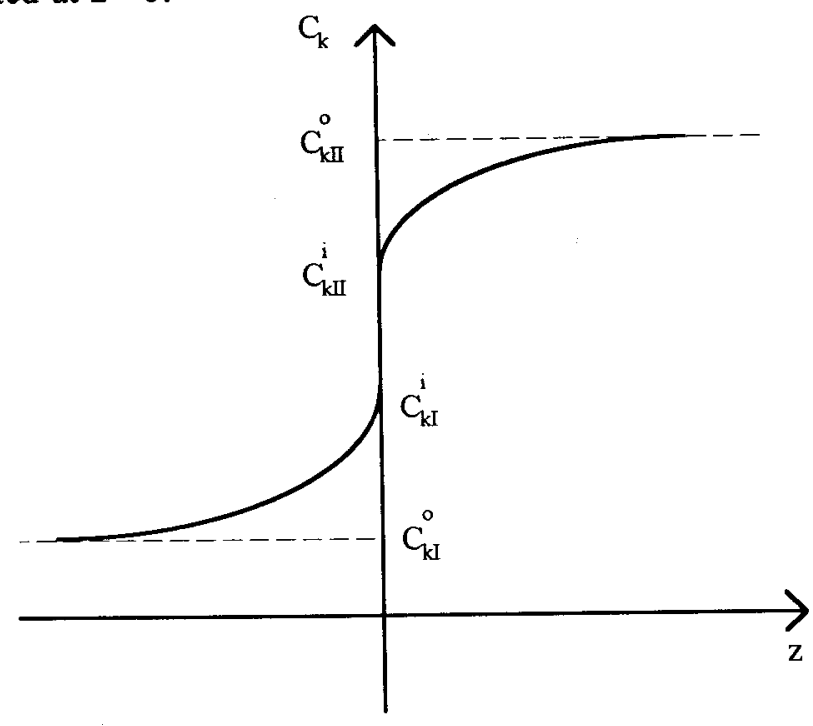

Figure 1: Concentration profile for component $k$. 
Transfer of mass involves small quantities and therefore movement of the interface with time is not significant and may be neglected. In addition, the assumption of dilute solutions allows use of Fick's second law (Bird et al., 1960). Therefore the concentration of component $k$ in both phases satisfies the following equations.

$$
\begin{array}{ll}
\frac{\partial \mathrm{C}_{\mathrm{kI}}}{\partial \mathrm{t}}=\mathrm{D}_{\mathrm{kI}} \frac{\partial^{2} \mathrm{C}_{\mathrm{kI}}}{\partial \mathrm{z}^{2}} & \text { for } \mathrm{z}<0 \\
\frac{\partial \mathrm{C}_{\mathrm{kII}}}{\partial \mathfrak{t}}=\mathrm{D}_{\mathrm{kII}} \frac{\partial^{2} \mathrm{C}_{\mathrm{kII}}}{\partial \mathrm{z}^{2}} & \text { for } z>0
\end{array}
$$

In the above expressions, $\mathrm{C}$ and $\mathrm{D}$ represent concentrations and diffusion coefficients respectively. In addition, subscripts I and II allow distinction between the two phases. Because of the assumption of dilute solutions, diffusion coefficients in mixtures may be assumed constant, and equal to binary diffusion coefficients.

For simplicity, we assume the initial concentrations in both phases to be independent of spatial positions:

$$
\begin{array}{ll}
\text { at } \quad \mathrm{t}=0, \mathrm{C}_{\mathrm{kI}}=\mathrm{C}_{\mathrm{kI}}^{\circ} & \text { for } \mathrm{z}<0 \\
\text { at } \mathrm{t}=0, \mathrm{C}_{\mathrm{kII}}=\mathrm{C}_{\mathrm{kII}}^{o} & \text { for } \mathrm{z}>0
\end{array}
$$

Superscript 0 is used in equations (3) and (4), to represent initial conditions, in conformity with the notations used by Bird et al. (1960).

Four boundary conditions are needed to solve the problem. Far from the interface, each phase does not feel the presence of the other phase, which means the concentrations remain unchanged at $z= \pm \infty$ :

$$
\begin{array}{lll}
\text { at } & \mathrm{z}=-\infty & \mathrm{C}_{\mathrm{kI}}=\mathrm{C}_{\mathrm{kI}}^{\circ} \\
\text { at } & \mathrm{z}=+\infty & \mathrm{C}_{\mathrm{kII}}=\mathrm{C}_{\mathrm{kII}}^{\circ}
\end{array}
$$


At the interface, we assume that equilibrium conditions are satisfied for all components present in both phases:

$$
\text { at } \quad \mathrm{z}=0 \quad \mathrm{C}_{\mathrm{kII}}^{\mathrm{i}}=\mathrm{m}_{\mathrm{k}} \mathrm{C}_{\mathrm{kI}}^{\mathrm{i}}
$$

In the above formula, $m$ represents distribution coefficients, and superscript $i$ is used to identify interfacial values.

In our analysis, we assume ideality, and therefore, distribution coefficients are assumed independent of compositions.

At the interface, there is no accumulation of mass, which means there is continuity of molar fluxes:

$$
\text { at } \quad \mathrm{z}=0, \quad-\mathrm{D}_{\mathrm{kI}} \frac{\partial \mathrm{C}_{\mathrm{kI}}}{\partial \mathrm{z}}=-\mathrm{D}_{\mathrm{kII}} \frac{\partial \mathrm{C}_{\mathrm{kII}}}{\partial \mathrm{z}}
$$

In our approximate boundary-layer approach, the following approximate concentrations profiles are used.

$$
\begin{aligned}
& \frac{C_{k I}-C_{k I}^{o}}{C_{k I}^{i}-C_{k I}^{o}}=f_{k I}\left(\frac{z}{-\delta_{k I}}\right) \quad \text { for: }-\delta_{k I}<z<0 \\
& \mathrm{C}_{\mathrm{kI}}=\mathrm{C}_{\mathrm{kI}}^{\mathrm{o}} \quad \text { for: } \mathrm{z}<-\delta_{\mathrm{kI}} \\
& \frac{\mathrm{C}_{\mathrm{kII}}-\mathrm{C}_{\mathrm{kII}}^{\mathrm{o}}}{\mathrm{C}_{\mathrm{kII}}^{\mathrm{i}}-\mathrm{C}_{\mathrm{kII}}^{\circ}}=\mathrm{f}_{\mathrm{kII}}\left(\frac{\mathrm{z}}{\delta_{\mathrm{kII}}}\right) \quad \text { for: } 0<\mathrm{z}<\delta_{\mathrm{kII}} \\
& \mathrm{C}_{\mathrm{kII}}=\mathrm{C}_{\mathrm{kII}}^{\mathrm{o}} \quad \text { for: } \mathrm{z}>\delta_{\mathrm{kII}}
\end{aligned}
$$




\section{INTEGRAL FORM OF THE GOVERNING EQUATIONS}

Integrating equation (1) with respect to $z$ from $z=-\delta_{k I}$ to $z=0$, while using Leibnitz formula, along with equation (10), we get

$\frac{d}{d t}\left(\int_{-\delta_{k I}}^{0} C_{k I} d z\right)-\frac{d \delta_{k I}}{d t} C_{k I}^{o}=D_{k I}\left(\frac{\partial C_{k I}}{\partial z}(0, t)-\frac{\partial C_{k I}}{\partial z}\left(-\delta_{k I}, t\right)\right)$

f represents approximate concentration profiles, and symbol $\delta$ is used to represent boundary-layer thicknesses.

Using the following notation

$$
\zeta_{\mathrm{kI}}=\frac{\mathrm{z}}{-\delta_{\mathrm{kI}}}
$$

equation (13) may be written, after simplification, in the following form

$$
\frac{\mathrm{d}}{\mathrm{dt}}\left[\left(\mathrm{C}_{\mathrm{kI}}^{\mathrm{i}}-\mathrm{C}_{\mathrm{kI}}^{\mathrm{o}}\right) \delta_{\mathrm{kI}} \int_{0}^{1} \mathrm{f}_{\mathrm{kI}} \mathrm{d} \zeta_{\mathrm{kI}}\right]=\frac{\mathrm{D}_{\mathrm{kI}}}{\delta_{\mathrm{kI}}}\left[\frac{\mathrm{df} f_{\mathrm{kI}}}{\mathrm{d} \zeta_{\mathrm{kI}}}(1)-\frac{\mathrm{df}_{\mathrm{kI}}}{\mathrm{d} \zeta_{\mathrm{kI}}}(0)\right]\left(\mathrm{C}_{\mathrm{kI}}^{\mathrm{i}}-\mathrm{C}_{\mathrm{kI}}^{\mathrm{o}}\right)
$$

In the same way, we get for phase II, after integration of equation (2) between $\mathrm{z}=0$ and $\mathrm{z}=\delta_{\mathrm{kII}}$

$$
\frac{\mathrm{d}}{\mathrm{dt}}\left(\int_{0}^{\delta_{\mathrm{kI}}} \mathrm{C}_{\mathrm{kII}} \mathrm{dz}\right)-\frac{\mathrm{d} \delta_{\mathrm{kII}}}{\mathrm{dt}} \mathrm{C}_{\mathrm{kII}}^{\mathrm{o}}=\mathrm{D}_{\mathrm{kII}}\left(\frac{\partial \mathrm{C}_{\mathrm{kII}}}{\partial \mathrm{z}}\left(\delta_{\mathrm{kII}}, \mathrm{t}\right)-\frac{\partial \mathrm{C}_{\mathrm{kII}}}{\partial \mathrm{z}}(0, \mathrm{t})\right)
$$

Introducing

$$
\zeta_{\mathrm{kII}}=\frac{\mathrm{z}}{\delta_{\mathrm{kII}}}
$$


we can write equation (15) as follows

$$
\begin{aligned}
\frac{d}{d t}\left[\left(C_{k I I}^{i}-C_{k I I}^{o}\right) \delta_{k I I} \int_{0}^{1} f_{k I I} d s_{k I I}\right] & \\
& \frac{D_{k I I}}{\delta_{k I I}}\left[\frac{d f_{k I I}}{d \varsigma_{k I I}}(1)-\frac{d f_{k I I}}{d \varsigma_{k I I}}(0)\right]\left(C_{k I I}^{i}-C_{k I I}^{o}\right)
\end{aligned}
$$

In addition, it is clear from initial conditions (3) and (4), that boundary layer thicknesses are initially equal to zero:

$$
\begin{array}{ll}
\text { at } \mathrm{t}=0 & \delta_{\mathrm{kI}}=0 \\
\text { at } \mathrm{t}=0 & \delta_{\mathrm{kII}}=0
\end{array}
$$

Finally, equation (8) may be written as

$$
\mathrm{D}_{\mathrm{kI}} \frac{\mathrm{C}_{\mathrm{kI}}^{\mathrm{i}}-\mathrm{C}_{\mathrm{kI}}^{\circ}}{\delta_{\mathrm{kI}}} \frac{\mathrm{df}_{\mathrm{kI}}}{\mathrm{d} \zeta_{\mathrm{kI}}}(0)=-\mathrm{D}_{\mathrm{kII}} \frac{\mathrm{C}_{\mathrm{kII}}^{\mathrm{i}}-\mathrm{C}_{\mathrm{kII}}^{\circ}}{\delta_{\mathrm{kII}}} \frac{\mathrm{df}_{\mathrm{kII}}}{\mathrm{d} \zeta_{\mathrm{kII}}}(0)
$$

\section{SOLUTION}

Concentration profiles are to be taken of the form

$$
f_{k I}\left(\varsigma_{k I}\right)=a_{0}+a_{1} \varsigma_{k I}+a_{2} \zeta_{k I}^{2}
$$

Imposing boundary condition (10) and continuity of the first derivative, concentration profiles are shown to be

$$
\mathrm{f}_{\mathrm{kI}}\left(\zeta_{\mathrm{kI}}\right)=\left(1-\zeta_{\mathrm{kI}}\right)^{2}
$$


The above approximate profile was mentioned by Bird et al. (1960), and used in the analysis of unsteady evaporation of a one- component liquid into a multicomponent vapor mixture.

Using equation (21) and substituting for concentration into equation (14) gives

$$
\frac{\mathrm{d}}{\mathrm{dt}}\left[\left(\mathrm{C}_{\mathrm{kI}}^{\mathrm{i}}-\mathrm{C}_{\mathrm{kI}}^{\mathrm{o}}\right) \delta_{\mathrm{kI}}\right]=6 \frac{\mathrm{D}_{\mathrm{kI}}}{\delta_{\mathrm{kI}}}\left(\mathrm{C}_{\mathrm{kI}}^{\mathrm{i}}-\mathrm{C}_{\mathrm{kI}}^{\circ}\right)
$$

For phase II, we also use

$$
\mathrm{f}_{\mathrm{kII}}\left(\zeta_{\mathrm{kII}}\right)=\left(1-\zeta_{\mathrm{kII}}\right)^{2}
$$

In the same way, we get

$$
\frac{\mathrm{d}}{\mathrm{dt}}\left[\left(\mathrm{C}_{\mathrm{kII}}^{\mathrm{i}}-\mathrm{C}_{\mathrm{kII}}^{\mathrm{o}}\right) \delta_{\mathrm{kII}}\right]=6 \frac{\mathrm{D}_{\mathrm{kII}}}{\delta_{\mathrm{kII}}}\left(\mathrm{C}_{\mathrm{kII}}^{\mathrm{i}}-\mathrm{C}_{\mathrm{kII}}^{\circ}\right)
$$

At this stage, we make the assumption that interfacial concentrations are independent of time. This assumption will be justified later.

Integrating equations (22) and (24) with respect to time, and using initial conditions (17) and (18) yields

$$
\begin{aligned}
& \delta_{\mathrm{kI}}=\sqrt{12 \mathrm{D}_{\mathrm{kI}} \mathrm{t}} \\
& \delta_{\mathrm{kII}}=\sqrt{12 \mathrm{D}_{\mathrm{kII}} \mathrm{t}}
\end{aligned}
$$

Using equations (21) and (23), we write equation (19) as follows

$$
\frac{\mathrm{C}_{\mathrm{kI}}^{\mathrm{i}}-\mathrm{C}_{\mathrm{kI}}^{\mathrm{o}}}{\mathrm{C}_{\mathrm{kII}}^{\mathrm{i}}-\mathrm{C}_{\mathrm{kII}}^{\mathrm{o}}}=-\frac{\mathrm{D}_{\mathrm{kII}}}{\mathrm{D}_{\mathrm{kI}}} \frac{\delta_{\mathrm{kI}}}{\delta_{\mathrm{kII}}}
$$

Combining the above expression with equations (7), (25) and (26) yields 


$$
\begin{gathered}
C_{k I}^{i}=\frac{C_{k I}^{o}+\sqrt{\frac{D_{k I I}}{D_{k I}}} C_{k I I}^{o}}{1+\sqrt{\frac{D_{k I I}}{D_{k I}}} m_{k}} \\
C_{k I I}^{i}=\frac{C_{k I I}^{o}+\sqrt{\frac{D_{k I}}{D_{k I I}}} C_{k I}^{o}}{1+\sqrt{\frac{D_{k I}}{D_{k I I}}} \frac{1}{m_{k}}}
\end{gathered}
$$

It is clear from expressions (28) and (29)

, that interfacial concentrations are independent of time, which justifies our previous assumption.

It is easy to prove that molar fluxes at the interface are

$$
\mathrm{N}_{\mathrm{k}, \mathrm{app} .}(0, \mathrm{t})=\frac{\mathrm{m}_{\mathrm{k}} \mathrm{C}_{\mathrm{kI}}^{o}-\mathrm{C}_{\mathrm{kII}}^{0}}{\mathrm{~m}_{\mathrm{k}}+\sqrt{\frac{\mathrm{D}_{\mathrm{kI}}}{\mathrm{D}_{\mathrm{kII}}}}} \sqrt{\frac{\mathrm{D}_{\mathrm{kI}}}{3 \mathrm{t}}}
$$

For single-component solutions, the exact value is

$$
N_{k, \text { exact }}(0, t)=\frac{m_{k} C_{k I}^{o}-C_{k I I}^{0}}{m_{k}+\sqrt{\frac{D_{k I}}{D_{k I I}}}} \sqrt{\frac{D_{k I}}{\pi t}}
$$

Comparing equations (30) and (31), we clearly see that the relative error is less than $2.5 \%$. 


\section{CONCLUSIONS AND RECOMMENDATIONS}

Results obtained by an approximate boundary--layer approach proved to be accurate in predicting mass transfer rates, when compared with the exact solution for dilute binary solutions.

Approximate techniques are powerful techniques, and it is recommended to extend the analysis to the case of interphase diffusion for concentrated solutions.

\section{REFERENCES}

1. W. R. Marshall, Jr., and R. L. Pigford, 1947, The application of Differential Equations to Chemical Engineering Problems, University of Delaware Press, Newark, Delaware, pp. 134136.

2. E. J. Scott, L. H. Tung, and H. G. Dickamer, 1951, J. Chem. Phys., 19, pp.075-1078 .

3. R. B. Bird, W. E. Stewart, E. N. Lightfoot, 1960, Transport Phenomena, John Wiley \& Sons, New York, pp. 602-605 \& pp. 624-625. 